\title{
The Beginnings and Development of
}

\section{German Business History}

By

Fritz Redlich 